\title{
SELEÇÃO RECORRENTE PARA TRÊS CARACTERES DO FEIJOEIRO ( $\left.{ }^{\mathbf{1}}\right)$
}

\author{
JOSÉ ÂNGELO NOGUEIRA DE MENEZES JÚNIOR $\left({ }^{2,4}\right)$; MAGNO ANTONIO PATTO RAMALHO $\left({ }^{2 *}\right)$; \\ ÂNGELA DE FÁTIMA BARBOSA ABREU $\left({ }^{3}\right)$
}

\begin{abstract}
RESUMO
O objetivo deste trabalho foi estimar o progresso genético após três ciclos de seleção recorrente na cultura do feijoeiro. Em cada ciclo, as progênies foram avaliadas por três gerações $S_{0: 1}, S_{0: 2}$ e $S_{0: 3}$, no campo experimental do Departamento de Biologia da Universidade Federal de Lavras (UFLA), em Lavras, Minas Gerais, no período de 2001 a 2006. Nos experimentos, avaliaram-se a produtividade de grãos, a arquitetura da planta e o tipo de grão. Em todas as avaliações de progênies, foram realizadas as análises de variância e obtidas as estimativas de parâmetros genéticos e fenotípicos. Foi estimado o progresso por caráter e, posteriormente, para os três caracteres, simultaneamente, após a padronização das variáveis. Como os ciclos foram obtidos em anos diferentes, utilizou-se o desempenho de duas linhagens que estiveram presentes em todas as avaliações para atenuar o efeito do ambiente nas estimativas obtidas. A diferença entre os $b^{\prime}$ s da regressão linear, entre o número de ciclos, variável independente $(x)$ e o desempenho médio do caráter sob seleção, variável dependente (y), das progênies e das testemunhas, forneceu a estimativa do progresso genético. Após três ciclos de seleção recorrente, o progresso genético foi de $3,1 \%$, considerando os três caracteres simultaneamente. A existência de variabilidade genética entre as progênies evidencia a possibilidade de continuar obtendo sucesso com a seleção.
\end{abstract}

Palavras-chave: Phaseolus vulgaris, progresso genético, regressão linear.

\section{ABSTRACT \\ RECURRENT SELECTION FOR THREE CHARACTERS IN COMMON BEAN}

The objective of this study was to estimate the genetic progress after three recurrent selection cycles in common bean. The progenies in each cycle were evaluated over three generations $S_{0: 1}, S_{0: 2}$ and $\mathrm{S}_{0: 3}$ on the experimental field of the Department of Biology at the Federal University of Lavras (UFLA), in Lavras, Minas Gerais, from 2001 to 2006. In the experiments, grain yield, grain type and plant architecture were evaluated. Analyses of variance and the estimates of genetic and phenotypic parameters were obtained in all progeny evaluations. The progress per trait was estimated and, upon standardization of variables, the progress for the three traits simultaneously. Since the cycles refer to different years, the performance of two lines that participated in all evaluations was used as base to lessen the environmental effect in the estimates. The difference between the $b^{\prime}$ s of the linear regression, of the number of cycles, the independent variable $(x)$, and the mean performance of the trait under selection, the dependent variable $(y)$, of the progenies and of the controls, provided the estimate of the genetic progress. Considering the three traits simultaneously after three recurrent selection cycles the genetic progress was $3.1 \%$ per cycle, The existence of genetic variability in the progenies suggests the possibility of continuous success with selection.

Key words: Phaseolus vulgaris, genetic progress, linear regression.

$\left({ }^{1}\right)$ Parte da Dissertação de mestrado em Genética e Melhoramento de Plantas, apresentado à UFLA, pelo primeiro autor. Recebido para publicação em 16 de março de 2007 e aceito em 26 de maio de 2008.

$\left({ }^{2}\right)$ Departamento de Biologia, Universidade Federal de Lavras (UFLA), Caixa Postal 3037, 37200-000 Lavras (MG). E-mail: jose.angelo@posgrad.ufla.br; magnoapr@ufla.br (*) Autor correspondente.

$\left({ }^{3}\right)$ Embrapa Arroz e Feijão/UFLA, Caixa Postal 3037, 37200-000 Lavras (MG). E-mail: afbabreu@ufla.br

$\left({ }^{4}\right)$ Bolsista da Fundação de Amparo à Pesquisa do Estado de Minas Gerais (FAPEMIG). 


\section{INTRODUÇÃO}

No caso do feijoeiro, no Brasil, entre os caracteres mais importantes para a aceitação de uma nova cultivar pelos agricultores estão a produtividade e o tipo de grãos e a arquitetura das plantas. As informações existentes do controle genético desses caracteres no feijoeiro comprovam que está envolvido grande número de genes. Além do mais, especialmente no caso da produtividade e da arquitetura, o efeito do ambiente é expressivo (TeixeIra et al., 1999; Bassett, 2004; Moreto et al., 2007).

Quando se deseja realizar o melhoramento para um ou mais caracteres, controlados por vários genes, é impossível se obter sucesso em um único ciclo seletivo. A principal alternativa é o emprego da seleção recorrente (Hallauer, 1992), isto é, um sistema cíclico e dinâmico que visa aumentar gradativamente a freqüência de alelos favoráveis para uma característica quantitativa, por meio de repetidos ciclos de seleção, avaliação e recombinação (GERALDI, 2005).

O sucesso da seleção recorrente em plantas alógamas é freqüentemente relatado (Helms et al., 1989; Weyhrich et al., 1998). No caso de plantas autógamas, já existem vários resultados que comprovam a sua eficiência quando se considera apenas um caráter (Holland et al., 2000; Wiersma et al., 2001). Não foram constatados, contudo, relatos de progresso genético com a seleção recorrente quando são considerados mais de um caráter simultaneamente.

A estimativa periódica do progresso genético na seleção recorrente é fundamental para orientar os melhoristas a respeito das estratégias seletivas utilizadas e quais as alternativas que poderiam ser adotadas para ampliar sua eficiência. Mediante o exposto, foi realizado o presente trabalho com o objetivo de estimar o progresso genético, após três ciclos de seleção recorrente, visando à obtenção de linhagens de feijão que associem alta produtividade, boa arquitetura e grãos comercialmente aceitos e, verificar se ainda há possibilidade de sucesso com a seleção.

\section{MATERIAL E MÉTODOS}

O programa de seleção recorrente foi desenvolvido na área experimental do Departamento de Biologia da Universidade Federal de Lavras (UFLA), no município de Lavras, Estado de Minas Gerais, situado a 918 metros de altitude, $21^{\circ} 14^{\prime} \mathrm{S}$ de latitude e $45^{\circ} 00^{\prime} \mathrm{W}$ de longitude.
A população-base foi obtida a partir do intercruzamento de dez linhagens de porte ereto, Carioca MG, CNFC 9454, CNFC 9455, CNFC 9458, CNFC 9466, CNFC 9471, CNFC 9484, IAPAR 81, LP 9876 todas de grãos tipo carioca, cor creme com estrias marrons e, a linhagem IPR Uirapuru, com grãos pretos. Os detalhes da obtenção da população do ciclo zero são apresentados por CuNHA et al. (2005) e o esquema adotado no desenvolvimento dos ciclos de seleção recorrente é apresentado na figura 1. Observe que foram avaliadas progênies $S_{0: 1}$ e $S_{0: 2}$ visando à seleção das melhores para a recombinação. As informações a respeito dos experimentos das avaliações das progênies estão apresentados na tabela 1 . Todos os experimentos foram submetidos aos mesmos tratos culturais, os quais são utilizados para a cultura do feijoeiro na região. A irrigação foi realizada, por aspersão, sempre que houve escassez de chuvas.

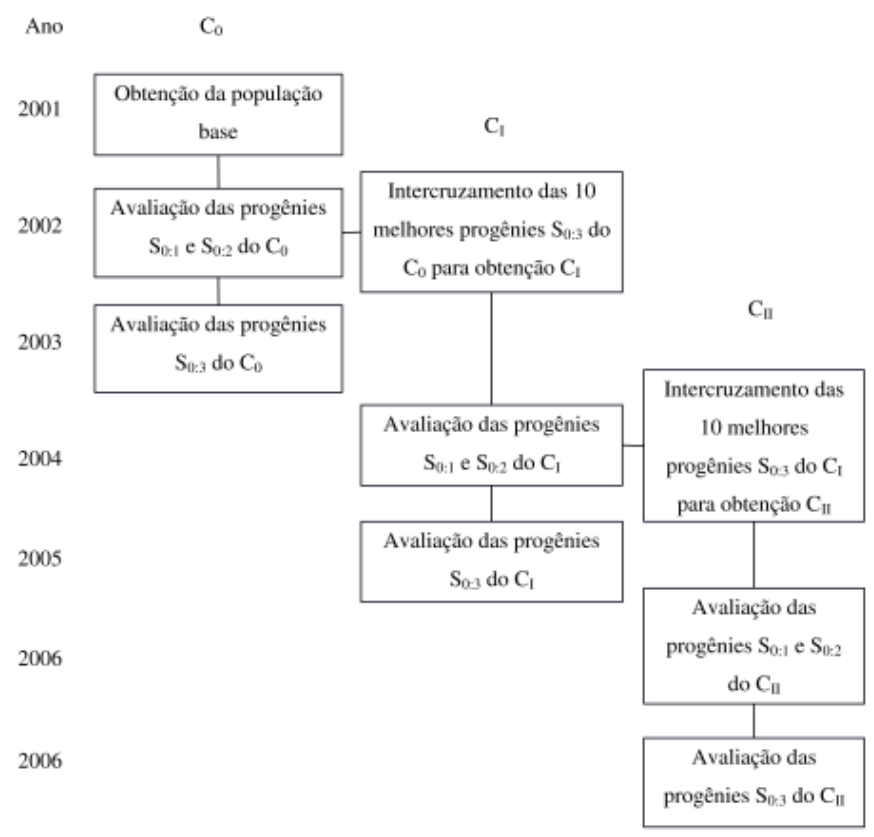

Figura 1. Esquema do programa de seleção recorrente visando à obtenção de linhagens produtivas de porte ereto e grão tipo carioca

Nos experimentos avaliaram-se a produtividade de grãos $\left(\mathrm{kg} \mathrm{ha}^{-1}\right)$, arquitetura da planta e o tipo de grão. A avaliação do porte foi realizada por meio de uma escala de notas modificada de ColLicchio et al. (1997). Essa escala varia de 1 a 5 em que: nota 5 refere-se à planta do tipo II, ereta, com uma haste e inserção alta das primeiras vagens e nota 1 à planta do tipo III, com entrenós longos e muito prostrada. O tipo de grão também foi avaliado utilizando uma escala de notas, modificada de RAMALHO et al. (1998), em que: nota 5 refere-se ao grão típico carioca, de cor creme com estrias marrom-claras, fundo claro, halo creme, massa média de cem sementes de 22 a 24 g e não achatado, e nota 1 refere-se ao grão com deficiência em todas as características do grão carioca comercial. 
Tabela 1. Detalhes experimentais da avaliação das progênies segregantes nos três ciclos de seleção recorrente

\begin{tabular}{|c|c|c|c|c|c|c|c|c|c|}
\hline & \multicolumn{3}{|c|}{ Ciclo $\mathrm{C}_{0}$} & \multicolumn{3}{|c|}{ Ciclo $C_{I}$} & \multicolumn{3}{|c|}{ Ciclo $C_{I I}$} \\
\hline & $S_{0: 1}$ & $\mathrm{~S}_{0: 2}$ & $S_{0: 3}$ & $S_{0: 1}$ & $S_{0: 2}$ & $S_{0: 3}$ & $S_{0: 1}$ & $\mathrm{~S}_{0: 2}$ & $S_{0: 3}$ \\
\hline Progênies & 190 & 134 & 60 & 390 & 186 & 54 & 390 & 186 & 62 \\
\hline Testemunhas & 10 & 10 & 4 & 10 & 10 & 10 & 10 & 10 & 2 \\
\hline Ano & 2002 & $2002 / 03$ & 2003 & 2004 & 2004 & 2005 & 2005/06 & 2006 & 2006 \\
\hline Safra & Inverno & Águas & Seca & Seca & Inverno & Seca & Águas & Seca & Inverno \\
\hline Delineamento & DBC & Látice & Látice & Látice & Látice & Látice & Látice & Látice & Látice \\
\hline Repetições & 2 & 3 & 3 & 2 & 2 & 3 & 2 & 3 & 3 \\
\hline Parcela & $\begin{array}{l}1 \text { linha } \\
\text { de } 1 \mathrm{~m}\end{array}$ & $\begin{array}{l}2 \text { linhas } \\
\text { de } 2 \mathrm{~m}\end{array}$ & $\begin{array}{l}2 \text { linhas } \\
\text { de } 2 \mathrm{~m}\end{array}$ & $\begin{array}{l}1 \text { linha } \\
\text { de } 2 \mathrm{~m}\end{array}$ & $\begin{array}{l}2 \text { linhas } \\
\text { de } 2 \mathrm{~m}\end{array}$ & $\begin{array}{l}2 \text { linhas } \\
\text { de } 2 \mathrm{~m}\end{array}$ & $\begin{array}{l}1 \text { linha } \\
\text { de } 2 \mathrm{~m}\end{array}$ & $\begin{array}{l}2 \text { linhas } \\
\text { de } 2 \mathrm{~m}\end{array}$ & $\begin{array}{c}2 \text { linhas } \\
\text { de } 2 \mathrm{~m}\end{array}$ \\
\hline $\begin{array}{l}\text { Caracteres } \\
\text { avaliados }\end{array}$ & $\begin{array}{l}\text { Produção } \\
\text { Porte }\end{array}$ & $\begin{array}{l}\text { Produção } \\
\text { Porte }\end{array}$ & $\begin{array}{c}\text { Produção } \\
\text { Porte }\end{array}$ & $\begin{array}{l}\text { Produção } \\
\text { Porte }\end{array}$ & $\begin{array}{l}\text { Produção } \\
\text { Porte }\end{array}$ & $\begin{array}{l}\text { Produção } \\
\text { Porte }\end{array}$ & $\begin{array}{l}\text { Produção } \\
\text { Porte }\end{array}$ & $\begin{array}{c}\text { Produção } \\
\text { Porte }\end{array}$ & $\begin{array}{l}\text { produção } \\
\text { Porte }\end{array}$ \\
\hline & - & - & Grão & Grão & Grão & Grão & Grão & Grão & Grão \\
\hline
\end{tabular}

Como todas as pressuposições da análise de variância foram aceitas, os dados da produtividade de grãos e das notas de porte e de grãos, sem transformação, foram submetidos à análise de variância, por geração e, posteriormente, realizada a análise de variância conjunta utilizando as médias ajustadas dos tratamentos comuns às gerações $\mathrm{S}_{0: 1}, \mathrm{~S}_{0: 2}$ e $\mathrm{S}_{0: 3}$, em cada ciclo. Para realizar as análises de variância, foi utilizado o programa estatístico Mstat-c Michigan State University (1991). Com base nas esperanças dos quadrados médios, considerando todos os efeitos do modelo aleatório, exceto a média, foram estimadas as variâncias genética $\left(\sigma_{P}^{2}\right)$, fenotípica $\left(\sigma_{F}^{2}\right)$ e da interação progênies $x$ gerações $\left(\sigma_{P_{x} G}^{2}\right)$ (Ramalho, et al 2005b). Estimou-se também a herdabilidade no sentido amplo $\left(\mathrm{h}^{2}\right)$ para a seleção na média das progênies (VencovsKy e BARRIGA, 1992).

O progresso genético (PG) com a seleção recorrente foi obtido utilizando as médias das dez melhores progênies utilizadas no processo de recombinação em cada ciclo. Foi estimado inicialmente o progresso por caráter. Como os ciclos foram obtidos em anos diferentes, utilizou-se o desempenho de duas linhagens que estiveram presentes em todas as avaliações (CNFC 9466 E CNFC 9455), para estimar o efeito do ambiente (anos) nas estimativas obtidas. A diferença entre os b's da regressão linear, do número de ciclos, variável independente e o desempenho médio do caráter sob seleção, variável dependente, das progênies e das testemunhas, forneceu a estimativa do progresso genético: $P G(\%)=\left[\left(b_{1 p}-b_{1 t}\right) / b_{0 p}\right] \times 100$, em que: $b_{1 p}$ : coeficiente de regressão linear do desempenho médio das dez progênies utilizadas na recombinação, em função dos diferentes ciclos de seleção; $b_{1 t}$ : coeficiente de regressão linear do desempenho médio das testemunhas comuns nos diferentes ciclos de seleção; $b_{0 p}$ : intercepto da equação de regressão linear do desempenho médio das dez progênies utilizadas na recombinação, em função dos diferentes ciclos de seleção;

Posteriormente, estimou-se o PG para os três caracteres simultaneamente. Como a produtividade de grãos (g) é obtida em $\mathrm{kg} \mathrm{ha}^{-1}$ e o porte (p) e o tipo de grão (s) por meio de uma escala de notas, foi necessário padronizar os dados, visando torná-los diretamente comparáveis. A variável padronizada $Z$ foi obtida pelo seguinte estimador (STEEL et al, 1997): $Z=x-m / s$, em que $x$ é a média do caráter considerado da progênie i; m média de todas as progênies, $\mathrm{s}$ desvio-padrão entre média das progênies. Como a variável padronizada assume valores negativos e positivos, foi adicionada uma constante, o valor 3 , a fim de se ter todos os dados positivos. Após a padronização de cada caráter, foi obtido o somatório por progênie, ou seja, o valor associado à progênie $i$ foi a soma da padronização obtida para $\sum Z=Z_{g}+Z_{p}+Z_{s}$. Utilizando essa soma, de modo análogo ao já comentado para os caracteres individualmente, foi estimado o progresso genético considerando os três caracteres simultaneamente.

\section{RESULTADOS E DISCUSSÃO}

Foi detectada diferença significatica $(P \leq 0,01)$ entre as progênies em praticamente todos os experimentos, verificando-se variação entre elas para os três caracteres nos ciclos seletivos. A interação progênies $x$ gerações foi não significativa nos dois primeiros ciclos para produtividade de grãos e notas de porte; já no terceiro ciclo foi detectada interação significativa $(\mathrm{P} \leq 0,05)$. 
A estimativa do componente de variância progênies x gerações $\left(\sigma_{P_{X}}^{2}\right)$ diferiu entre os ciclos (Tabela 2). Ela foi nula (estimativa negativa) para produtividade de grãos no ciclo zero e muito expressiva nos ciclos um e dois. Na maior parte dos trabalhos realizados na região para produtividade de grãos a interação progênies $x$ safras tem sido expressiva (CARNEIRO et al. 2002; Silva et al., 2004; Moreto et al., 2007). A estimativa de $\sigma_{P x G}^{2}$ foi também expressiva, sobretudo no ciclo 0 . A ocorrência de interação para as notas de porte tem sido também relatadas na literatura (CollicCHIO et al., 1997; TeIXEIRA et al., 1999; CunHa et al., 2005). As estimativas de $\hat{\sigma}_{P}^{2}$ confirmam a existência de variabilidade genética entre as progênies. Observe que todas as estimativas do limite inferior de $\hat{\sigma}_{P}^{2}$ foram positivos, indicando que a variância de progênies é diferente de zero ao nível de $95 \%$ de probabilidade. De modo geral, não ocorreu diferença expressiva nas estimativas de $\hat{\sigma}_{P}^{2}$ comparando o primeiro e o último ciclo seletivo. Esses resultados estimulam a continuidade do processo de seleção, pois não houve indícios de redução da variabilidade genética na população, o que possibilita antever a possibilidade de obter sucesso, com a seleção recorrente, em ciclos futuros.

As estimativas de herdabilidade para a produtividade de grãos foram muito semelhantes entre os ciclos e, com $95 \%$ de probabilidade, são diferentes de zero (Tabela 2). Estimativas de herdabilidade de magnitude semelhante são constatadas na literatura
(RAmalho et al., 2005a; Amaro et al, 2006). No caso da nota de porte, as estimativas de $\mathrm{h}^{2}$ variaram entre os ciclos, sendo inferior no $\mathrm{C}_{0}$, inclusive com chance de assumir valor nulo, limite inferior da estimativa negativo. Convém mencionar que essas estimativas da $\mathrm{h}^{2}$ são no sentido amplo, pois a variância genética entre progênies contém, além da variância aditiva $\left(\sigma_{A}^{2}\right)$, também a variância de dominância $\left(\sigma_{D}^{2}\right)$, isto é: $S_{0: 1}=1 \sigma_{A}^{2}+1 / 4 \sigma_{D}^{2}, S_{0: 2}=1 \sigma_{A}^{2}+1 / 16 \sigma_{D}^{2}$ e $S_{03}=1 \sigma_{A}^{2}+1 / 64 \sigma_{D}^{2}$. Como a dominância para esses caracteres não é expressiva no feijoeiro (MORETo et al., 2007), infere-se que grande parte da variância presente no numerador da $\mathrm{h}^{2}$ deve ser aditiva.

O progresso genético com a seleção recorrente variou entre os caracteres (Tabela 3). Ele foi maior para o tipo de grão e até negativo com relação ao porte, visto que a seleção foi efetuada para os três caracteres ao mesmo tempo, ou seja, entre as dez progênies selecionadas não necessariamente estavam as de melhor arquitetura, sendo também considerados a produtividade e o tipo de grão. Tem sido difícil associar porte ereto e tamanho (massa) de grãos dentro do padrão comercial (Collichio et al, 1997), bem como com a maior produtividade de grãos (Cunha et al, 2005). Contudo, a média padronizada das notas de porte, no terceiro ciclo, possibilita inferir que nas dez progênies selecionadas, a nota de porte das plantas foi próximo do que é almejado. É necessário, entretanto, continuar a seleção com ênfase na identificação de linhagens com porte ereto, alta produtividade e grãos dentro do padrão comercial.

Tabela 2. Estimativas da variância genética entre médias de progênies $\left(\hat{\sigma}_{P}^{2}\right)$, variância fenotípica na média das progênies $\left(\hat{\sigma}_{\bar{F}}^{2}\right)$, variância da interação progênies x gerações $\left(\hat{\sigma}_{P_{X G}}^{2}\right)$ e herdabilidade $\left(\mathrm{h}^{2}\right)$ na média das progênies, obtidas para produtividade de grãos $\left(\mathrm{kg} \mathrm{ha}^{-1}\right)$ e notas de porte e tipo de grão nos diferentes ciclos de seleção recorrente

\begin{tabular}{|c|c|c|c|c|c|c|c|c|c|}
\hline \multirow{2}{*}{ Estimativas } & \multicolumn{3}{|c|}{ Produtividade } & \multicolumn{3}{|c|}{ Nota de porte } & \multicolumn{3}{|c|}{ Nota de tipo de grão } \\
\hline & $\mathrm{C}_{0}$ & $\mathrm{C}_{\mathrm{I}}$ & $\mathrm{C}_{\mathrm{II}}$ & $\mathrm{C}_{0}$ & $\mathrm{C}_{\mathrm{I}}$ & $\mathrm{C}_{\mathrm{II}}$ & $\mathrm{C}_{0}\left({ }^{3}\right)$ & $\mathrm{C}_{\mathrm{I}}$ & $\mathrm{C}_{\mathrm{II}}$ \\
\hline & & $-\mathrm{kg} \mathrm{ha}^{-1}$ & & & & & & & \\
\hline$\hat{\sigma}_{P}^{2}$ & 37121,7 & 51463,9 & 42568,2 & 0,016 & 0,031 & 0,029 & - & 0,080 & 0,018 \\
\hline $\operatorname{LI}\left({ }^{1}\right)$ & 29238,5 & 40130,3 & 33827,7 & 0,013 & 0,024 & 0,023 & - & 0,059 & 0,015 \\
\hline LS & 48704,6 & 68409,6 & 55214,9 & 0,021 & 0,041 & 0,038 & - & 0,115 & 0,023 \\
\hline$\hat{\sigma}_{\bar{F}}^{2}$ & 75593,0 & 109230,6 & 97373,1 & 0,058 & 0,071 & 0,053 & - & 0,093 & 0,053 \\
\hline$\hat{\sigma}_{P_{X G}}^{2}$ & $-11433,6$ & 27501,3 & 34326,4 & 0,022 & 0,004 & 0,014 & - & $-0,095$ & 0,043 \\
\hline $\mathrm{h}^{2}(\%)$ & 49,1 & 47,1 & 43,7 & 28,2 & 43,8 & 53,7 & - & 85,7 & 34,4 \\
\hline $\mathrm{LI}\left({ }^{2}\right)$ & 21,9 & 16,9 & 14,2 & $-10,2$ & 11,6 & 29,3 & - & 77,6 & $-0,04$ \\
\hline LS & 68,2 & 67,6 & 64,3 & 54,8 & 65,5 & 70,6 & - & 91,2 & 58,4 \\
\hline
\end{tabular}

(1) LI - limite inferior e LS limite superior da estimativa (Ramalho et al., 2005b).

$\left({ }^{2}\right)$ LI - limite inferior e LS limite superior da estimativa (Knapp et al., 1985).

(3) Para nota de tipo de grão as estimativas só puderam ser obtidas nos ciclos $C_{I}$ e $C_{I I}$. 
Tabela 3. Médias da produtividade de grãos e notas de porte e tipo de grão das dez progênies utilizadas na recombinação $\left(\bar{P}^{i}\right)$, das testemunhas $\left(\overline{T_{i}}\right)$ e somatório da variável padronizada $(\Sigma Z)$, nos diferentes ciclos de seleção recorrente, com seus respectivos valores de $b_{0}, b_{1}, R^{2}$ e estimativas do progresso genético (PG)

\begin{tabular}{|c|c|c|c|c|c|c|c|c|}
\hline \multirow{2}{*}{ Ciclo } & \multicolumn{2}{|c|}{ Produtividade } & \multicolumn{2}{|c|}{ Nota de porte } & \multicolumn{2}{|c|}{ Nota de tipo de grão } & \multicolumn{2}{|c|}{$\sum Z$} \\
\hline & $\bar{P}_{i}$ & $\overline{t_{i}}$ & $\bar{P}_{i}$ & $\bar{t}_{i}$ & $\bar{P}_{i}$ & $\bar{t}_{i}$ & $\bar{P}_{i}$ & $\bar{t}_{i}$ \\
\hline & 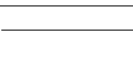 & -1 & & & & & & \\
\hline $\mathrm{C}_{0}$ & 2450.32 & 2110.29 & 3.85 & 3.94 & 2.88 & 3.08 & 8.81 & 8.84 \\
\hline$C_{I}$ & 2859.92 & 2678.65 & 3.56 & 4.25 & 3.67 & 2.81 & 9.61 & 8.68 \\
\hline $\mathrm{C}_{\mathrm{II}}$ & 3232.27 & 2762.98 & 3.46 & 3.95 & 3.73 & 3.35 & 9.84 & 9.36 \\
\hline $\mathrm{b}_{0}$ & 2065.55 & 1864.62 & 4.01 & 4.04 & 2.58 & 2.81 & 8.39 & 8.44 \\
\hline$b_{1}$ & 390.97 & 326.35 & -0.20 & 0.005 & 0.43 & 0.14 & 0.52 & 0.26 \\
\hline $\mathrm{R}^{2}(\%)$ & 99.92 & 84.50 & 92.67 & 0.08 & 80.25 & 25.00 & 90.7 & 53.5 \\
\hline PG(\%) & 3.13 & - & -5.11 & - & 11.24 & - & 3.10 & - \\
\hline
\end{tabular}

Estimativas do PG com a seleção recorrente visando à produtividade de grãos no feijoeiro são relativamente freqüentes na literatura (RANALLI, 1996; BARRON et al., 1999; SingH et al., 1999; RAMALHO et al., 2005a), porém as metodologias empregadas geralmente são diferentes, o que dificultam as comparações.

Para estimar o progresso genético para os três caracteres simultaneamente, foi obtido o somatório dos valores de Z, que representa um índice de seleção, em que as três variáveis têm massa igual. Aqui, as testemunhas comuns também foram incluídas porque as médias e as variâncias utilizadas na obtenção de $\mathrm{Z}$ variaram entre os ciclos, com possível efeito ambiental. Nesse caso, o procedimento foi semelhante ao utilizado para cada caráter separadamente. Portanto, após três ciclos de seleção recorrente o progresso genético para os três caracteres, simultaneamente, foi de $3,1 \%$ por ciclo, indicando que a seleção recorrente foi eficiente na obtenção de progênies produtivas, de porte ereto e com grão tipo carioca. Infelizmente, não foram encontrados, na literatura, relatos de pesquisas que possibilitassem a comparação com as estimativas do presente trabalho.

\section{CONCLUSÕES}

1. O progresso genético com a seleção recorrente foi de $3,1 \%$ por ciclo, considerando a produtividade, a arquitetura da planta e o tipo de grão, simultaneamente.

2. A variabilidade genética presente na população evidencia a possibilidade de se continuar obtendo sucesso com a seleção.

\section{AGRADECIMENTOS}

À Fundação de Amparo à Pesquisa do Estado de Minas Gerais (FAPEMIG), pelo apoio financeiro.

\section{REFERÊNCIAS}

AMARO, G.B.; RAMALHO, M.A.P.; ABREU, A.F.B.;SILVA, F.B. Phenotypic.recurrent selection in the common bean (Phaseolus vulgaris L.) with carioca-type grains for resistance to the fungi Phaeoisariopsis griseola. Genetics and Molecular Biology, Ribeirão Preto, v. 30, n 3, p. 584-588, 2007.

BARRON,J.E.; PASINI, R.J.; DAVIS, D.W.; STUTHMAN, D.D.; GRAHAM, P.H. Response to selection for seed yield and nitrogen $\left(\mathrm{N}_{2}\right)$ fixation in common bean (Phaseolus vulgaris L.). Field Crops Research, Amsterdam, v. 62, n. 2/3, p. 119-128, 1999.

BASSET, M.J. List of genes - Phaseolus vulgaris L. Annual Report of the Bean Improvement Cooperative, Fort Collins, n. 47 p. $1-24,2004$.

CARNEIRO, J.E.S.; RAMALHO, M.A.P.; ABREU, A.F.B.; GONÇALVES, F.M.A. Breeding potential of single, double and multiple crosses in common bean. Crop Breeding and Applied Biotechnology, Londrina, v. 2, p. 515-524, 2002.

COLLICCHIO, E.; RAMALHO, M.A.P.; ABREU, A.F.B. Associação entre o porte da planta do feijoeiro e o tamanho dos grãos. Pesquisa Agropecuária Brasileira, Brasília, v. 32, n. 3, p. 297-304, 1997.

CUNHA, W.G.; RAMALHO, M.A.P.; ABREU, A.F.B. Selection aiming at upright growth habit common bean with carioca type grains. Crop Breeding and Applied Biotechnology, Londrina, v. 5, p. 379-386, 2005. 
GERALDI, I. O. Por que realizar seleção recorrente? In: SIMPÓSIO DE ATUALIZAÇÃO EM GENÉTICA E MELHORAMENTO DE PLANTAS, 9., 2005, Lavras. Anais... Lavras: UFLA, Programa de Pós-Graduação em Agronomia/ Genética e Melhoramento de plantas, 2005. p. 1-8.

HALLAUER, A.R. Recurrent selection in maize. Plant Breeding Reviews, New York, v. 9, p. 115-179, 1992.

HELMS, T.C.; HALLAUER, A.R.; SMITH, O.S. Genetic drift and selection evaluated from recurrent selection programs in maize. Crop Science, Madison, v. 29, n. 3, p.602-607, 1989.

HOLLAND, J.B.; BJØRNSTAD, Å.; FREY, K.J.; GULLORD, M.; WESENBERG D.M.; BURAAS, T. Recurrent selection in oat for adaptation to diverse environments. Euphytica, Wageningen, v. 113, n. 1, p. 195-205, 2000.

KNAPP, S.J.; STROUP, W.W.; ROSS, W.M. Exact confidence intervals for heritability on a progeny mean basis. Crop Science, Madison, v. 25, n. 1, p. 192-194, 1985.

MORETO, A.L.; RAMALHO, M.A.P.; NUNES, J.A.R.; ABREU, A.F.B. Estimação dos componentes da variância fenotípica em feijoeiro utilizando método genealógico.Ciência e Agrotecnologia, Lavras, v. 31, n. 4, p. 1035-1042, 2007.

MSTAT-C. A software program for the design, management and analysis of agronomic research experiments. [S.1]: Michigan State University, 1991. p. ir.

RAMALHO, M.A.P.; ABREU, A.F.B.; SANTOS, J.B. Genetic progress after four cycles of recurrent selection for yield and grain traits in common bean. Euphytica, Wageningen, v. 144, p. 23-29, 2005a.

RAMALHO, M.A.P.; FERREIRA, D.F.; OLIVEIRA, A.C. Experimentação em genética e melhoramento de plantas. 2.ed. Lavras: UFLA, 2005b. 322p.

RAMALHO, M.A.P.; PIROLA, L.H.; ABREU, A.F.B. Alternativas na seleção de plantas de feijoeiro com porte ereto e grão tipo carioca. Pesquisa Agropecuária Brasileira, Brasília, v. 33, n. 12, p. 1989-1994, 1998.

RANALLI, P. Phenotypic recurrent selection in common bean (Phaseolus vulgaris L.) based on performance of $S_{2}$ progenies. Euphytica, Wageningen, v. 87, n. 2, p. 127-132, 1996.

SILVA, N.O.; RAMALHO, M.A.P.; ABREU, A.F.B.; CARNEIRO, J.E.S. Performance of common bean families after different generations under natural selection. Genetics and Molecular Biology, Ribeirão Preto, v.27, n. 4, p. 574-578, 2004.

SINGH, S.P.; TERÁN, H.; MUÑOZ, C.G.; TAKEGAMI, J.C. Two cycles of recurrent selection for seed yield in common bean. Crop Science, Madison, v. 39, n. 2, p. 391-397, 1999.

STEEL, R.G.D.; TORRIE, J.H.; DICKEY, D.A. Principles and Procedures of Statistics a Biometrical Approach. 3 ed. Nova York: McGraw-Hill, 1997. 666p.

TEIXEIRA, F.F.; RAMALHO, M.A.P.; ABREU, A.F.B. Genetic control of plant architecture in the common bean (Phaseolus vulgaris L.). Genetics and Molecular Biology, Ribeirão Preto, v. 22, n. 4, p. 577-582, 1999.

VENCOVSKY, R. \& BARRIGA, P. Genética biométrica no fitomelhoramento. Ribeirão Preto: Sociedade Brasileira de Genética, 1992. 496p.

WEYHRICH, R.A.; LAMKEY, K.R.; HALLAUER, A.R. Responses to seven methods of recurrent selection in the BS11 maize population. Crop Science, Madison, v. 38, n. 2, p. 308321, 1998.

WIERSMA, J.J.; BUSCH, R.H.; FULCHER, G.G.; HARELAND, G.A. Recurrent selection for kernel weight in spring wheat. Crop Science, Madison, v. 41, n. 4, p. 999-1005, 2001. 